\title{
UJI AKTIVITAS ANTIMIKROBA SERTA ANTIOKSIDAN ASAP CAIR \\ CANGKANG SAWIT (Elaeis gueneensis jack)
}

\author{
Yefrida, Refilda, Indrawati, dan Irma Yanti Siregar \\ Jurusan Kimia, FMIPA, Universitas Andalas \\ email : yefanwar@gmail.com
}

\begin{abstract}
Liquid smoke is one of natural preservative. It can make from many sources such as coconut shell, wood, etc. In this study, it is made from the palm kernel shell (Elaeis gueneensis jack) by using pirolysis method. Its contains is determined by GC-MS, while antimicrobial activity by KirbyBauer method and antioxidant activity by DPPH method. From the test, it can be concluded that this liquid smoke contains carboxylic acids, fenol and its derivative compound as a major component and has a good enough antimicrobial and antioxydant activity.
\end{abstract}

Keywords : liquid smoke, pirolysis, antimicrobial, antioxvdant.

\section{DAFTAR PUSTAKA}

1. P. Darmaji, 1996, Aktivitas antibakteri Asap Cair yang Diproduksi dari Bermacam-Macam Limbah Pertanian, Agritech, 16(4),19-22.

2. Yefrida, Y. K. Putri, R. Silvianti, , N. Lucia, Refilda, Indrawati, 2008, Pembuatan asap cair dari limbah kayu suren (Toona sureni), sabut kelapa dan tempurung kelapa (Cocos nucifera Linn), Jurnal Riset Kimia, 1(2), 187-191.

3. Yefrida, I. T. Leone, F. Aprilina, M. Salim, Refilda, 2009, Uji sifat anti bakteri asap cair yang berasal dari batang kayu manis dan kulit kacang tanah, Jurnal Riset Kimia, Vol. 2 No. 2, Hal 189-193

4. P. Almunady dan N. Syarif. Uji Daya Hambat Asap Cair Hasil Pirolisis Kayu Pelawan(Tristania Abavata) Terhadap Bakteri Echerichia Coli, 2009, Jurnal Penelitian Sains

5. F.Swastawati, T. W. Agustini, Y. S. Darmanto, E. N. Dewi, 2007, Liquid Smoke Performance of Lamtoro Wood and Corn Cob. J. Coastal Development. 10(3), 189-196

6. S. Ramakrishnan, P. Moeller, Liquid Smoke : Product of Hardwood Pyrolysis, 2002, Fuel Chemistry Division Reprints, 47(1), 366-367.

7. M. D. Guillen, M. L. Ibargotia, 1998, New Components with Potential Antioxidant and Organoleptic Properties, Detected for the First Time in Liquid Smoke Flavoring Preparations, J. Agric.Food Chem., 46, 1276-1285

8. I. Zuraida, Sukarno, S. Budijanto, 2011, Antibacterial Activity of Coconut Shell Liquid Smoke (CS-LS) and Its Application on Fish Ball Preservation, International Food Research Journal, $18,405-410$

9. P. Darmaji, 1996, Produksi Asap Cair dan Sifat-Sifat Antimikrobia, Antioksidan serta Sensorisnya, Laporan Penelitian Mandiri, DPP-UGM, 19; 11-15

10. S. Budijanto, R. Hasbullah, S. Prabawati, Setiadjit, Sukarno, I. Zuraida, 2008, kajian Keamanan Asap Cair Tempurung Kelapa untuk Produk Pangan, Jurnal Ilmu Pertanian Indonesia, 13(3), 194-203

11. T. Hattula, K. Elfving, U. M. Mrouch, T. Luoma, 2001, Use of Liquid Smoke Flavoring as an Alternative to Traditional Flue Gas Smoking of Rainbow Trout Fillets (Oncorhyncus mykiss), Lebensmittel Wissenschaft un Technologie,34, 521-525 
12. P. Molyneux, 2004, The use the stable free radical diphenylpicrylhydrazyl (DPPH) for estimating antioxidant activity. J. Sci. Technol, 26, 2, 211-219

13. N. Yuliana, 2011, Pembuatan, Karakterisasi dan Uji Aktivitas Antimikroba dan Antioksidan dari Batang Jambu Biji, Skripsi Sarjana Kimia, Unand.

14. A. H. Ningsih, 2011, Pembuatan, Karakterisasi dan Uji Aktivitas Antimikroba dan Antioksidan dari Tandan Salak, Skripsi Sarjana Kimia, Unand. 